\title{
Note on translation, transliteration, and informed consent
}

THE fieldwork for this research and film project was carried out in a mixture of Danish, Arabic, and English. While most sermons and prayers in the mosques of Aarhus would be conducted in classical Arabic with occasional translations into Danish, many of the conversations between my interlocutors often occurred in a combination of Danish, English, and colloquial Arabic (mainly Palestinian and Iraqi dialects). While some of the people I worked with speak Arabic fluently, many of my Afghan, Somali, and Turkish interlocutors, and some of the young Arabs, often preferred to speak in Danish. My language skills allowed me to understand and identify the main content of sermons and conversations in Arabic, but many of the details I have had translated subsequently with the kind help of people from the mosques.

Throughout the chapters and the film I have translated both Danish and Arabic quotations into English. When meanings of particular words could be interpreted in divergent ways I have included original phrases in parentheses. In addition many of the standard Islamic greetings, supplications, and concepts such as sihr (magic) or khushū' (humility) have been kept in Arabic to convey the flavour of the communication, which often fluctuated indistinctly between the different linguistic registers.

For the transliteration of Arabic words and phrases I generally adopted the system outlined in the International Journal of Middle East Studies. For ease of reading I have omitted diacritical marks for place names, proper names, and the names of my interlocutors. For words such as Quran, hadith, or the category of invisible spirits called jinn I have used their customary English spelling. Rather than distinguishing between jinn (plural), jinnī (singular masculine), and jinnīyya (singular feminine), I use jinn in both singular and plural as is common in English (Oxford English Dictionary 2013). For Quranic verses I generally use M.A. S. Abdel Haleem's (2005) translation. In addition I sometimes rely on translations and interpretations of particular Quranic concepts provided by my interlocutors in the mosques. In subtitling the film, many of the Quranic verses and Islamic supplications have been severely shortened and abridged in order to ease viewing. 
When people have explicitly asked to remain anonymous or when I have judged it necessary to keep the identities of particular individuals private, their names and backgrounds have been changed. In the film I have concealed the identity of a number of people through the editing and framing of images. The people who do appear with their own names in the film and book have all been informed about the scope and aims of the research project and have explicitly given their consent. After a number of preliminary screenings of the film and discussions of the written text, I have adjusted the editing and writing according to the requests of those who appear in it.

My interlocutors in the mosques and in Danish psychiatry all had their own, and sometimes conflicting, reasons for participating in this research project. Some nurses and psychiatrists expressed a strong need for more knowledge about the treatment of Muslim patients. Furthermore some expressed a wish to demystify and illustrate how psychiatric encounters actually take place. Similarly, among the people I worked with in the mosques, many expressed a wish to show a side of their religious practice that seldom reaches public debates about Islam in the West. Some participated in the project in the hope that it might highlight something of the truth or strength of Islam, and perhaps even become a form of da'wa (invitation to Islam). I have attempted to take all of these desires and requests seriously so as to establish the research process as a collaborative project. Therefore it is my interlocutors' interpretations and translations of their own practices that provide the starting point for my analysis. Yet I am painfully aware that the book and film fulfil only to a very limited degree the ambitions of all my interlocutors. The book and film present my best efforts to provide a fair account of the religious and psychiatric treatments experienced by patients. Any responsibility for flaws, biases, and omissions within the analysis is entirely mine. 